\title{
Lower Education and Household Income Contribute to Advanced Disease, Less Treatment Received and Poorer Prognosis in Patients with Hepatocellular Carcinoma
}

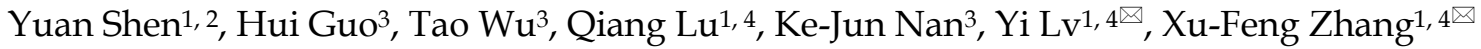 \\ 1. Department of Hepatobiliary Surgery, the First Affiliated Hospital of Xi' an Jiaotong University, Xi' an, 710061, Shaanxi Province, China; \\ 2. Department of Epidemiology and Health Statistics, School of Public Health, Xi' an Jiaotong University Health Science Center; \\ 3. Department of Oncology, the First Affiliated Hospital of Xi' an Jiaotong University, Xi' an, 710061, Shaanxi Province, China; \\ 4. Institute of Advanced Surgical Technology and Engineering, the First Affiliated Hospital of Xi'an Jiaotong University, Xi' an, 710061, Shaanxi Province, \\ China.
}

$\square$ Corresponding authors: Xu-Feng Zhang, MD, PhD, Associated Professor, Department of Hepatobiliary Surgery, The First Affiliated Hospital of Xi'an Jiaotong University, 277 West Yanta Road, Xi'an, China Phone: 862985323626 Email: xfzhang125@xjtu.edu.cn Yi Lv, MD, PhD, Professor, Department of Hepatobiliary Surgery, The First Affiliated Hospital of Xi'an Jiaotong University, 277 West Yanta Road, Xi'an, China Phone: 862985323900 Email: luyi169@126.com

(c) Ivyspring International Publisher. This is an open access article distributed under the terms of the Creative Commons Attribution (CC BY-NC) license (https://creativecommons.org/licenses/by-nc/4.0/). See http://ivyspring.com/terms for full terms and conditions.

Received: 2017.03.04; Accepted: 2017.06.01; Published: 2017.09.02

\begin{abstract}
Understanding the ways in which socioeconomic status affects prognosis of hepatocellular carcinoma (HCC) is important for building up strategies eliminating the inequalities in cancer diagnosis and treatments among different groups, which, remains undetermined. In the present study, 1485 newly diagnosed HCC patients with complete demographic and clinical data were included. Socioeconomic data, including education, annual household income and residency was also reported by patients or families. In the present study, less educated patients were older, more female involved, poorly paid, more living in rural places, had more advanced tumor burden, received less curative and loco-regional therapies, and thus showed poorer short-term and long-term outcomes (in total or after surgical resection) than the highly educated. Patients with lower income were less educated, less treated, and more likely to live in rural places, had more advanced stages of HCC and thus poorer long-term survival (in total or after surgical resection) than higher income groups. In Cox regression analysis, lower household income was independently associated with poorer outcome $(\mathrm{HR}=1.2,95 \% \mathrm{Cl}: 1.0-1.4, p=0.036)$. These results indicate that education and income are critically associated with early diagnosis, treatments and prognosis of HCC. Much more efforts should be taken to support the patients with less education and lower income to improve the outcomes of HCC.
\end{abstract}

Key words: Hepatocellular carcinoma; surgery; education; income; survival.

\section{Introduction}

Hepatocellular carcinoma (HCC) is the second most common cause of cancer-related death all over the world, with China alone accounting for more than $50 \%$ of the total number of cases and deaths [1-3]. Fewer than $20 \%$ of patients with HCC are amendable to curative surgical resection and liver transplantation [4]. Most patients presented with advanced staged
HCC were treated with loco-regional therapies (LRT) or only supportive care. Despite the availability and improvement of different therapies, overall survival of patients with HCC remains poor with an overall 1-year survival rate of less than $50 \%$ [5].

Despite the substantial advances in knowledge concerning risk factors of patient survival including 
demographic, tumor- and treatments-related factors, socioeconomic inequalities which persist in cancer incidence, morbidity, mortality, and survival, have been largely neglected [6-8]. Some socioeconomic factors, such as education and household income, can be closely related to comorbidity status, health awareness and adherence to treatments, which are also likely to affect the timing of referral, tumor stage at diagnosis and treatment choices after diagnosis. Some studies have implied that higher education level and household income were associated with a beneficial effect of survival of certain cancer patients [6, 9-12]. However, some studies indicated that the effects of socioeconomic status might be restricted in some high-mortality cancers $[11,13]$.

As a type of malignancy with high mortality associated, HCC has not been thoroughly studied about potential influence of socioeconomic status on diagnosis, treatments and prognosis. One study using Surveillance, Epidemiology and End Results (SEER) database demonstrated that higher income, longer education and living in large urban areas were correlated with prolonged survival of patients with unresectable HCC [14]. However, HCC staging (Barcelona Clinic Liver Cancer [BCLC]) and actual treatments were unavailable in the study [14]. Therefore, the present study aimed to identify whether socioeconomic disparities as measured by education and household income affect BCLC stages at diagnosis, receipt of treatments, and overall survival among patients with HCC.

\section{Patients and Methods}

1622 patients firstly diagnosed as HCC January 2008 to September 2013 in our hospital were included retrospectively. The demographic information, Child-Pugh class, hepatitis status and residence place were documented before the primary treatments. Primary treatments were defined as liver transplant and surgical resection when the patients underwent liver transplant surgical resection during follow up regardless of other treatments received. LRT included radiofrequency ablation, microwave ablation, ethanol intratumoral injection, transarterial chemoembolization (TACE) and palliative resection. Supportive treatments were defined as those with no tumor-target therapy but only nutritional support or no specific treatments.

The education level and household income were reported by the patients or their family members, and documented during follow up. The information was obtained with the understanding of the patients and/or their relatives that it might be published with no identified personal information. The education level were classified as below high school level (less than 9 years of education), high school level (10-12 years of education), and above high school level ( $\geq 13$ years of education). The household income included the self-reported annual income of the patients and their spouses, which were categorized as low income ( $\leq 50,000$ Chinese Yuan [CNY]), moderate income $(50,000-200,000 \mathrm{CNY})$ and high income $(>200,000$ CNY).

15 patients younger than 25 years old were excluded, since they were still studying in school and had no personal income yet. 122 patients unresponsive to the education and income information were excluded. Finally, 1485 patients were included in the present study. The study has been approved by the ethics committee of the First Affiliated Hospital Xi'an Jiaotong University. A waiver of informed consent was obtained, since the data were analyzed from the electronic medical record and reported without personal identifiers.

\section{Statistical analysis}

Numerical variables were expressed as mean \pm standard deviation, and compared with One-way ANOVA test among the groups, and with student $t$ test or Mann-Whitney U test between the two groups. Nominal variables were expressed as number and percentages, and compared with Chi-squared test or Fisher's exact test. Kaplan-Meier survival analysis was used to compare survival with log-rank test among the three groups and between any two groups. Cox regression was used to assess the association of potential risk factors including education and income of overall survival expressed by hazard ratio (HR) and 95\% confidence interval $(\mathrm{CI})$. Two-tailed $p$ value $<$ 0.05 was considered statistically significant. Statistical analysis was carried out using SPSS 22.0 (Chicago, IL, USA).

\section{Results}

\section{Correlation of education level with clinical parameters}

Among the 1485 patients, most (60.7\%) had education for 10 to 12 years equal to high school level, 21.1\% were educated for more than 13 years, and $18.1 \%$ for less than 9 years. Patients educated below high school level were older, more female involved, less paid, more living in rural places, and less curatively or loco-regionally treated with a higher 90-day mortality than other two groups, respectively (all $p<0.05$, Table 1). Child-Pugh class of liver function was similar among the three groups. However, patients educated for at least 13 years equal to college level were much more highly paid and more likely to live in large cities than other two less educated groups 
(all $p<0.05$, Table 1). Patients educated above high school level were more likely to have early BCLC staged HCC at diagnosis, and receive curative and loco-regional therapies than other two groups (all $p<0.05$, Table 1 ).

Table 1. Demographic and treatments of the patients at different education level

\begin{tabular}{|c|c|c|c|c|}
\hline Variables & $\begin{array}{l}\text { Below high } \\
\text { school } \\
(n=269)\end{array}$ & $\begin{array}{l}\text { High school } \\
\text { level } \\
(n=902)\end{array}$ & $\begin{array}{l}\text { Above high } \\
\text { school } \\
(\mathrm{n}=314)\end{array}$ & P value \\
\hline Age (years) & $57 \pm 11^{1,2 ; 1,3}$ & $54 \pm 12$ & $55 \pm 14$ & $<0.001$ \\
\hline Male gender & $192(71.4 \%)^{1,2 ; 1,3}$ & $744(82.5 \%)$ & $269(85.7 \%)$ & $<0.001$ \\
\hline Child-Pugh class & & & & 0.204 \\
\hline A & $232(8.6 \%)$ & $799(8.9 \%)$ & $263(8.4 \%)$ & \\
\hline B & $32(11.9 \%)$ & $92(10.2 \%)$ & $47(15.0 \%)$ & \\
\hline $\mathrm{C}$ & $5(1.9 \%)$ & $11(1.2 \%)$ & $4(1.3 \%)$ & \\
\hline Household income* & 1,$2 ; 1,3$ & 2,3 & & $<0.001$ \\
\hline$\leq 50,000 \mathrm{CNY}$ & $136(50.6 \%)$ & $189(10.9 \%)$ & $15(4.8 \%)$ & \\
\hline $50,000-200,000 \mathrm{CNY}$ & $110(40.9 \%)$ & $529(58.6 \%)$ & $123(39.2 \%)$ & \\
\hline$>200,000 \mathrm{CNY}$ & $20(7.4 \%)$ & $178(19.7 \%)$ & $176(56.1 \%)$ & \\
\hline Residence & 1,$2 ; 1,3$ & 2,3 & & $<0.001$ \\
\hline Rural/small urban & $221(82.2 \%)$ & $434(48.1 \%)$ & $27(8.6 \%)$ & \\
\hline Large urban & $48(17.8 \%)$ & $468(51.9 \%)$ & $287(91.4 \%)$ & \\
\hline Hepatitis status & 1,3 & & & 0.021 \\
\hline Hepatitis B/C & $192(71.4 \%)$ & $705(78.2 \%)$ & $253(80.5 \%)$ & \\
\hline None & $77(28.6 \%)$ & $197(21.8 \%)$ & $61(19.4 \%)$ & \\
\hline $\begin{array}{l}\text { First Dept. } \\
\text { admitted }\end{array}$ & & & & 0.408 \\
\hline Surgery Dept. & $166(61.7 \%)$ & $690(76.5 \%)$ & $260(82.8 \%)$ & \\
\hline $\begin{array}{l}\text { Internal Medical } \\
\text { Dept. }\end{array}$ & $91(33.8 \%)$ & $198(22.0 \%)$ & $50(15.9 \%)$ & \\
\hline Other Dept. & $12(4.5 \%)$ & $14(15.5 \%)$ & $4(1.3 \%)$ & \\
\hline BCLC stages & 1,3 & 2,3 & & 0.027 \\
\hline $0-\mathrm{A}$ & $105(39.0 \%)$ & $336(37.3 \%)$ & $144(45.9 \%)$ & \\
\hline B-D & $164(61.0 \%)$ & $566(62.7 \%)$ & $170(54.1 \%)$ & \\
\hline Primary treatments & 1,$2 ; 1,3$ & 2,3 & & $<0.001$ \\
\hline Liver transplant & $2(0.7 \%)$ & $15(1.7 \%)$ & $17(5.4 \%)$ & \\
\hline Surgical resection & $117(43.5 \%)$ & $384(42.6 \%)$ & $122(38.9 \%)$ & \\
\hline $\begin{array}{l}\text { Locoregional } \\
\text { therapies }\end{array}$ & $117(43.5 \%)$ & $437(48.4 \%)$ & $148(47.1 \%)$ & \\
\hline $\begin{array}{l}\text { Supportive } \\
\text { treatments }\end{array}$ & $33(12.3 \%)$ & $66(7.3 \%)$ & $27(8.6 \%)$ & \\
\hline 30-day mortality & $16(5.9 \%)$ & $47(5.2 \%)$ & $12(3.8 \%)$ & 0.475 \\
\hline 90-day mortality & $39(14.5 \%)^{1,2 ; 1,3}$ & $88(9.8 \%)$ & $28(8.9 \%)$ & 0.045 \\
\hline
\end{tabular}

\section{Correlation of household income with clinical parameters}

The self-reported annual household income was categorized as low, moderate and high in 1476 patients ( 9 patients declined to report their household incomes). Patients with low income were less educated, more likely to live in rural places and had more advanced BCLC stages of HCC than either moderate or high income patients (all $p<0.05$, Table 2 ). Moreover, patients with low income were less treated (although not statistically different) and displayed higher 30-day mortality than other two groups (both $p<0.05$, Table 2). Patients with high income had better liver function classified by Child-Pugh score at admission, and were more likely to live in large cities than those with low and moderate income (all $p<0.05$, Table 2).

Table 2. Demographic and treatments of the 1476 patients with different household income

\begin{tabular}{|c|c|c|c|c|}
\hline Variables & $\begin{array}{l}\text { Low income } \\
(n=340)\end{array}$ & $\begin{array}{l}\text { Moderate income } \\
(\mathrm{n}=762)\end{array}$ & $\begin{array}{l}\text { High income } \\
(n=374)\end{array}$ & $\begin{array}{l}\mathrm{P} \\
\text { value }\end{array}$ \\
\hline Age (years) & $55 \pm 12$ & $54 \pm 12^{2,3}$ & $56 \pm 13$ & 0.020 \\
\hline Male gender & $270(79.4 \%)$ & $625(82.0 \%)$ & $303(81.0 \%)$ & 0.590 \\
\hline Child-Pugh class & 1,3 & 2,3 & & $<0.001$ \\
\hline A & $309(90.9 \%)$ & $672(88.2 \%)$ & $304(81.3 \%)$ & \\
\hline B & $28(8.2 \%)$ & $77(10.1 \%)$ & $66(17.6 \%)$ & \\
\hline $\mathrm{C}$ & $3(0.8 \%)$ & $13(1.7 \%)$ & $4(1.1 \%)$ & \\
\hline Residence & 1,$2 ; 1,3$ & 2,3 & & $<0.001$ \\
\hline Rural/small urban & $236(69.4 \%)$ & $334(43.8 \%)$ & $103(27.5 \%)$ & \\
\hline Large urban & $104(30.6 \%)$ & $428(56.2 \%)$ & $271(72.5 \%)$ & \\
\hline Hepatitis status & & & & 0.083 \\
\hline Hepatitis B/C & $249(73.3 \%)$ & $595(78.0 \%)$ & $299(80.0 \%)$ & \\
\hline Others & $91(26.8 \%)$ & $167(21.9 \%)$ & $75(20.1 \%)$ & \\
\hline $\begin{array}{l}\text { First Dept. } \\
\text { admitted }\end{array}$ & & & & 0.449 \\
\hline Surgery Dept. & $235(69.1 \%)$ & $564(74.0 \%)$ & $308(82.4 \%)$ & \\
\hline $\begin{array}{l}\text { Internal Medical } \\
\text { Dept. }\end{array}$ & $98(28.8 \%)$ & $183(24.0 \%)$ & $58(15.5 \%)$ & \\
\hline Other Dept. & $7(2.1 \%)$ & $15(2.0 \%)$ & $8(2.1 \%)$ & \\
\hline BCLC stages & 1,$2 ; 1,3$ & & & 0.001 \\
\hline $0-\mathrm{A}$ & $105(30.9 \%)$ & $310(40.7 \%)$ & $165(44.1 \%)$ & \\
\hline B-D & $235(69.1 \%)$ & $452(59.3 \%)$ & $209(55.9 \%)$ & \\
\hline Primary treatments & & & & 0.081 \\
\hline Liver transplant & $2(0.6 \%)$ & $19(2.5 \%)$ & $13(3.5 \%)$ & \\
\hline Surgical resection & $150(44.1 \%)$ & $312(41.0 \%)$ & $154(41.1 \%)$ & \\
\hline $\begin{array}{l}\text { Locoregional } \\
\text { therapies }\end{array}$ & $151(44.4 \%)$ & $369(48.4 \%)$ & $180(48.1 \%)$ & \\
\hline $\begin{array}{l}\text { Supportive } \\
\text { treatments }\end{array}$ & $37(10.9 \%)$ & $62(8.1 \%)$ & $27(7.2 \%)$ & \\
\hline 30-day mortality & $26(7.6 \%)^{1,2 ; 1,3}$ & $33(4.3 \%)$ & $16(4.3 \%)$ & 0.049 \\
\hline 90-day mortality & $44(12.9 \%)$ & $79(10.4 \%)$ & $32(8.6 \%)$ & 0.159 \\
\hline
\end{tabular}

\section{Socioeconomic factors and patients survival}

The overall 1-, 3- and 5-year survival rates of all the patients were $77 \%, 43 \%$ and $20 \%$, respectively. The survival curves of the patients at different education level were plotted by Kaplan-Meier method in Figure 1A. Patients educated above high school had significant prolonged survival than those educated at or below high school level (Median survival 47 vs. 37 months, $p=0.028$; and 47 vs. 35 months, $p=0.010$ ) (Figure 1A). The 1-, 3- and 5-year survival rates were $72 \%, 41 \%$ and $17 \%$ in patients educated below high school, $78 \%, 43 \%$ and $17 \%$ at high school level, and $81 \%, 47 \%$ and $31 \%$ above high school level, respectively ( $p=0.019$, , Figure $1 \mathrm{~A})$.

When stratified by household income, patients with high income had significantly better prognosis than other two groups (Median survival, 46 months vs. 37 months and 34 months, $p=0.003$ and $p<0.001$, respectively) (Figure 1B). The 1-, 3- and 5-year survival rates were $75 \%, 39 \%$ and $14 \%$ in patients with 
low income, $77 \%, 41 \%$ and $18 \%$ in patients with moderate income, and $80 \%, 50 \%$ and $30 \%$ in patients

A

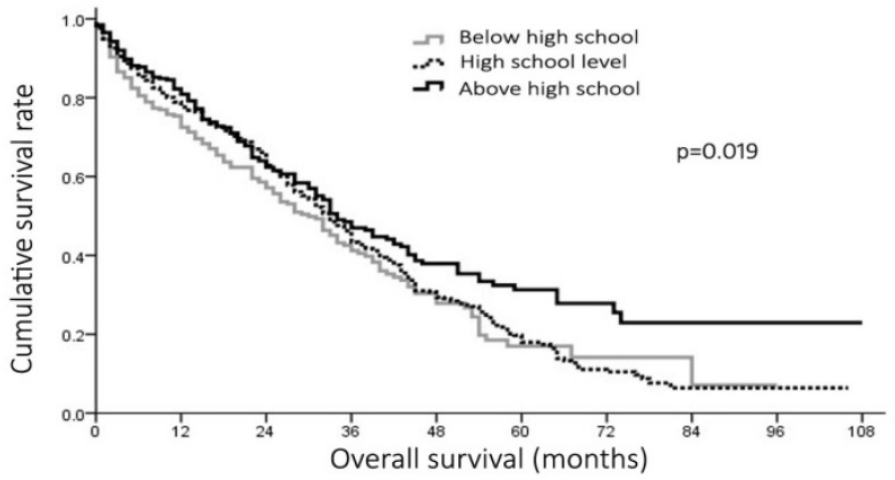

patients at risk

$\begin{array}{rllllllllll}\text { Below } & 269 & 185 & 121 & 64 & 36 & 11 & 3 & 2 & 1 & - \\ \text { Above } & 902 & 674 & 461 & 239 & 112 & 45 & 18 & 4 & 2 & - \\ \text { Abohool } & 247 & 158 & 93 & 48 & 27 & 12 & 6 & 4 & 1\end{array}$

B

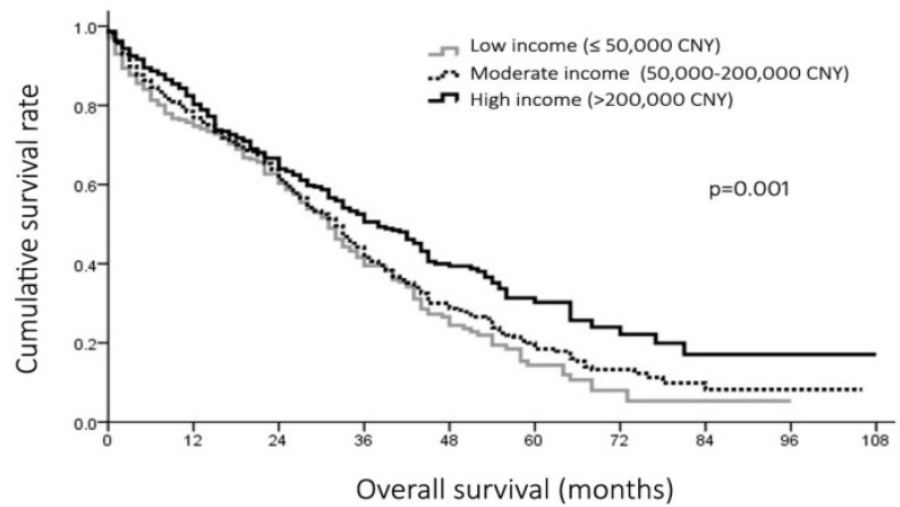

patients at risk

\begin{tabular}{|c|c|c|c|c|c|c|c|c|c|}
\hline Low & 340 & 234 & 162 & 78 & 37 & 14 & 3 & 1 & 1 \\
\hline Moderate & 762 & 562 & 350 & 183 & 87 & 40 & 17 & 6 & 3 \\
\hline High & 374 & 303 & 223 & 133 & 70 & 29 & 13 & 5 & 3 \\
\hline
\end{tabular}

C

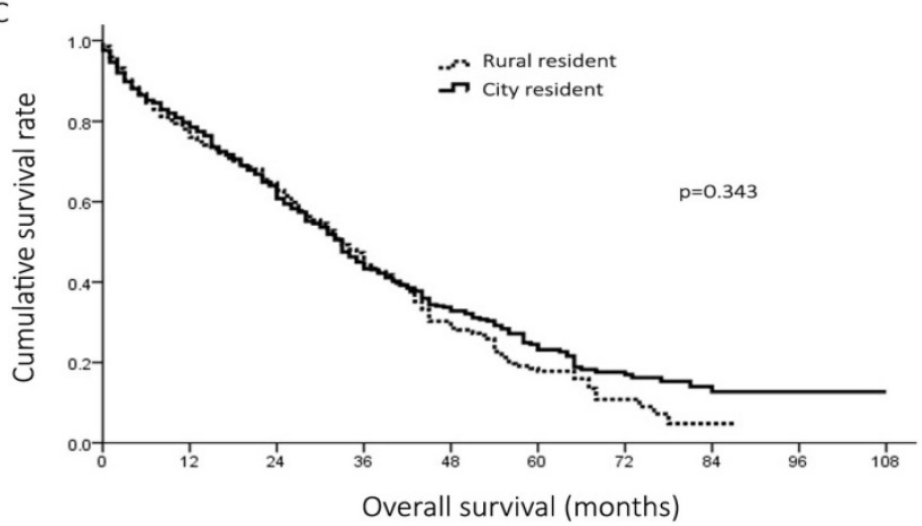

patients at risk

$\begin{array}{rllllllllll}\text { Rural } & 682 & 496 & 339 & 184 & 86 & 28 & 6 & 1 & - & - \\ \text { City } & 803 & 612 & 401 & 212 & 110 & 55 & 27 & 11 & 7 & 1\end{array}$

Figure 1. A, overall survival of 1485 patients with hepatocellular carcinoma $(\mathrm{HCC})$ at different education level; B, overall survival of $1476 \mathrm{HCC}$ patients with different annual household income; $\mathrm{C}$, overall survival of $1485 \mathrm{HCC}$ patients living in rural areas and city. with high income, respectively ( $p=0.001$, Figure 1B). In contrast, the survival was not different between the patients living in the rural/small urban and large urbans, (Median survival, 36 months vs. 41 months, $p=0.343$ ) (Figure 1C).

\section{Socioeconomic factors and patients survival after curative resection}

Totally, there were $623(42 \%)$ patients receiving curative surgical resection of HCC. Interestingly, there was no significant difference of the overall survival of the patients at different education background after curative resection ( $p=0.410$, Figure $2 \mathrm{~A})$. However, after surgical resection, patients with high income showed better prognosis than those with low and moderate income (Median survival, 45 months vs. 37 months and 35 months, $p=0.003$ and $p=0.015$, respectively) (Figure $2 \mathrm{~B}$ ). The $1-, 3$ - and 5 -year survival rates after surgery were $89 \%, 47 \%$ and $20 \%$ in patients with low income, $88 \%, 51 \%$ and $25 \%$ in patients with moderate income, and $92 \%, 66 \%$ and $30 \%$ in patients with high income, respectively $(p=0.010$, Figure 2B). Moreover, there was no difference of the overall survival of the HCC patients undergoing surgical resection living in large cities and those living in rural places $(p=0.111$, Figure $2 C$ ).

\section{Risk factors of HCC patient survival}

To better understand the potential risk factors associated with overall survival of patients, we performed univariate and multivariate analysis by Cox regression model (Table 3). By univariate analysis, Child-Pugh class B/C, lower education and household income, tumor size larger than $5 \mathrm{~cm}$, portal vein tumor thrombosis, and BCLC B, C and D versus 0-A were risk factors associated with poorer long-term survival (all $p<0.05$, Table 3 ), while radical and locoregional treatments were selected as protective factors associated with improved outcome versus supportive treatments (all $p<0.05$, Table 3). By multivariate analysis, Child-Pugh class B/C, advanced BCLC stages and lower household income were independently associated with poorer outcome (all $p<0.05$, Table 3), while HCC-directed therapies were associated with prolonged survival (all $p<0.05$, Table 3). 


\section{Discussion}

Few studies have been able to examine the

A

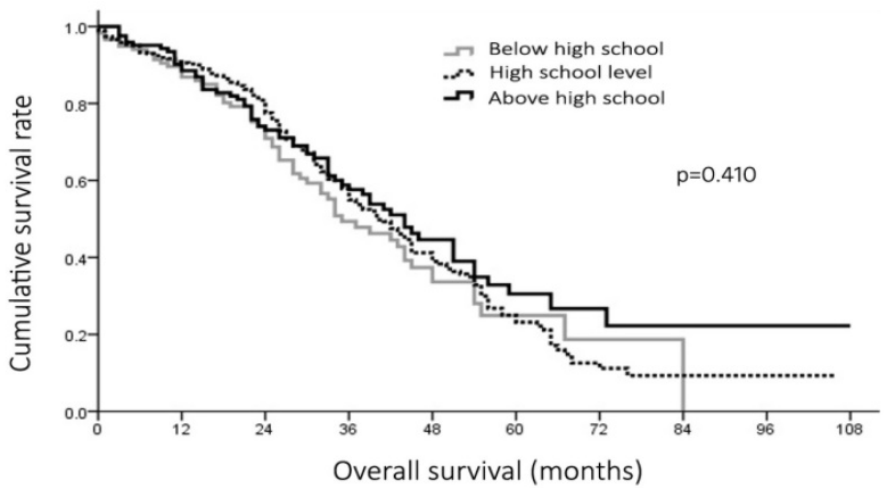

patients at risk

$\begin{array}{rllllllllll}\text { Below } & 117 & 98 & 69 & 34 & 20 & 8 & 1 & 1 & - & - \\ \text { gh school } & 384 & 338 & 245 & 140 & 74 & 27 & 9 & 2 & 2 & -\end{array}$

B

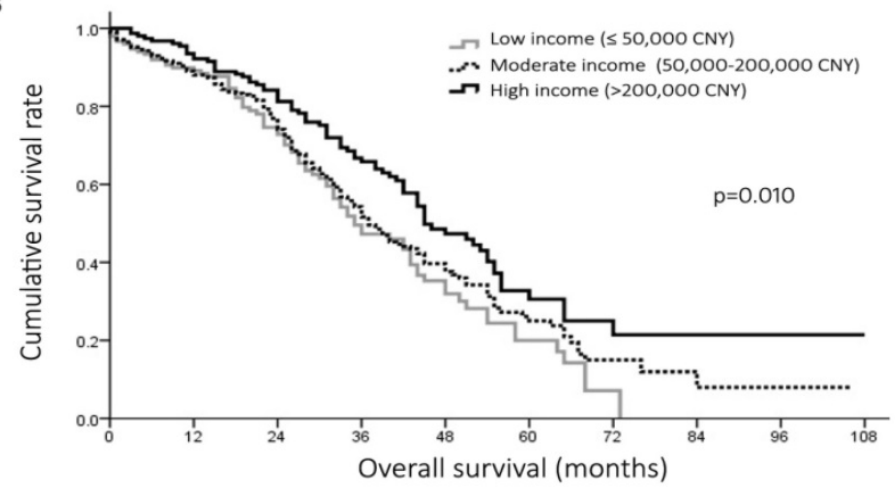

patients at risk

$\begin{array}{cllllllllll}\text { Low } & 150 & 125 & 83 & 43 & 21 & 9 & 1 & - & - & - \\ \text { Moderate } & 312 & 271 & 189 & 105 & 58 & 24 & 8 & 3 & 2 & - \\ \text { High } 154 & 143 & 116 & 73 & 39 & 15 & 7 & 2 & 1 & 1\end{array}$

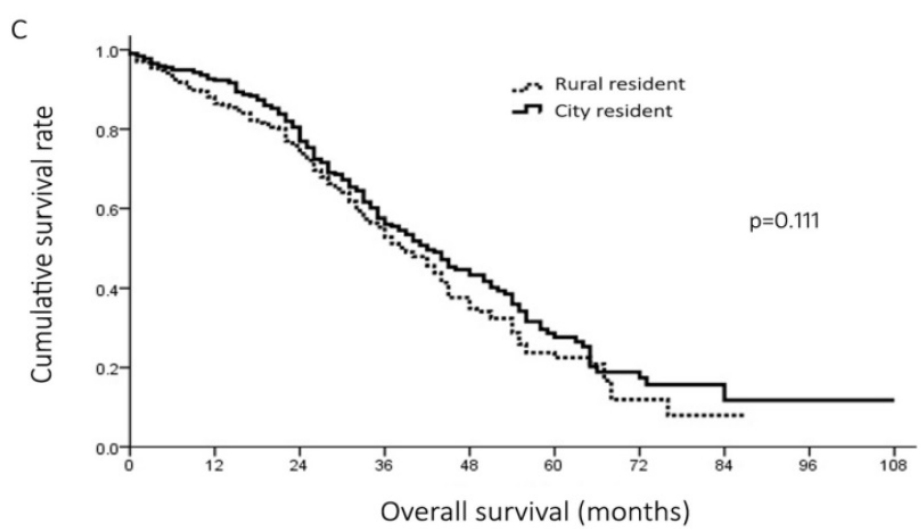

patients at risk

$\begin{array}{rllllllllll}\text { Rural } & 307 & 261 & 188 & 109 & 55 & 19 & 3 & 1 & - & - \\ \text { City } & 316 & 285 & 204 & 114 & 65 & 29 & 13 & 4 & 3 & 1\end{array}$

Figure 2. A, overall survival of 623 patients at different education level undergoing surgical resection hepatocellular carcinoma $(\mathrm{HCC})$; $B$, overall survival of 616 patients with different household income after surgical resection for HCC; $C$, overall survival of 623 patients living rural areas and city after surgical resection for $\mathrm{HCC}$. influence of socioeconomic status on prognosis of HCC patients. The present study demonstrated that in hospitalized HCC patients, lower education and household income were consistently associated with advanced BCLC stages at diagnosis, less treatment received and poorer long-term survival. It was well accepted that tumor stage and treatments were the most significant factors affecting prognosis of cancer patients. However, socioeconomic status has been neglected in determining screening, diagnosis, major and adjuvant treatments of cancer [6, 11, 12, 14-18]. Several studies using SEER-Medicare database have suggested that persistently poor long-term outcome across HCC population might be partially correlated with underutilization of effective HCC-directed therapies due to sociodemographic and economic factors [14-18]. Underutilization of effective therapies of HCC must be more severe in developing countries, such as China, because of traditional views of incurability of cancers, financial difficulties, and limited healthcare resources.

It is not surprising that education level is closely related to residency place, living habits, income, health insurance available, health care and disease treatments [6, 11, 12, 14-18]. However, due to the historical and social reasons, most patients $(902 / 1485,61 \%)$ in the present study (born before 1960s) were educated at high school level. The National College Entrance Examination of China had been restored since 1977, but with an average enrollment rate less than $5 \%$ at the beginning [19]. This was also confirmed by that highly educated patients were younger and more male predominant than less educated patients. Interestingly, less education was strongly correlated with more advanced disease, less HCC-target therapies received, higher 90-day mortality and poorer long-term survival. However, after surgical resection, no significant difference of survival was identified in patients at different education level (Figure 2A). These findings highlighted that less education was more likely to affect early detection of disease, access to care and choice of treatments of patients [16]. Once the patients were diagnosed and surgically treated, education level might be less important than other tumor- and treatment-related factors in affecting HCC outcome. 
Table 3. Univariate and multivariate analysis of the risk factors of survival for hepatocellular carcinoma

\begin{tabular}{|c|c|c|c|c|c|c|}
\hline \multirow[t]{2}{*}{ Variables } & \multirow[t]{2}{*}{$n$} & \multirow[t]{2}{*}{ events } & \multicolumn{2}{|l|}{ Univariate analysis } & \multicolumn{2}{|c|}{ Multivariate analysis } \\
\hline & & & HR (95\% CI) & P value & HR $(95 \%$ CI) & P value \\
\hline \multicolumn{7}{|l|}{ Age (years) } \\
\hline$\leq 50$ & 560 & 307 & 1 & & & \\
\hline$>50$ & 925 & 561 & $1.1(1.0-1.3)$ & 0.070 & & \\
\hline \multicolumn{7}{|l|}{ Gender } \\
\hline Female & 280 & 159 & 1 & & & \\
\hline Male & 1205 & 709 & $1.0(0.8-1.2)$ & 0.782 & & \\
\hline \multicolumn{7}{|l|}{ Child-Pugh class } \\
\hline A & 1294 & 733 & 1 & & 1 & \\
\hline $\mathrm{B} / \mathrm{C}$ & 191 & 135 & $1.9(1.5-2.2)$ & $<0.001$ & $1.6(1.3-1.9)$ & $<0.001$ \\
\hline \multicolumn{7}{|l|}{ Education } \\
\hline Above high school & 314 & 168 & 1 & & 1 & \\
\hline High school level & 902 & 537 & $1.2(1.0-1.4)$ & 0.031 & $1.2(0.9-1.5)$ & 0.217 \\
\hline Below high school & 269 & 163 & $1.3(1.1-1.7)$ & 0.007 & $1.2(1.0-1.4)$ & 0.118 \\
\hline \multicolumn{7}{|l|}{ Residence } \\
\hline Rural/small urban & 682 & 401 & $1.1(0.9-1.2)$ & 0.349 & & \\
\hline Large urban & 803 & 467 & 1 & & & \\
\hline \multicolumn{7}{|l|}{ Household income } \\
\hline$>200,000 \mathrm{CNY}$ & 374 & 211 & 1 & & 1 & \\
\hline $50,000-200,000 \mathrm{CNY}$ & 762 & 443 & $1.3(1.1-1.5)$ & 0.004 & $1.2(1.0-1.4)$ & 0.069 \\
\hline$\leq 50,000 \mathrm{CNY}$ & 340 & 210 & $1.4(1.2-1.7)$ & 0.001 & $1.2(1.0-1.4)$ & 0.036 \\
\hline \multicolumn{7}{|l|}{ Tumor size } \\
\hline$<5 \mathrm{~cm}$ & 808 & 448 & 1 & & 1 & \\
\hline$\geq 5 \mathrm{~cm}$ & 677 & 420 & $1.3(1.2-1.5)$ & $<0.001$ & $1.1(0.8-1.3)$ & 0.507 \\
\hline \multicolumn{7}{|l|}{ Tumor number } \\
\hline$\leq 3$ & 1296 & 750 & 1 & & & \\
\hline$>3$ & 189 & 118 & $1.2(0.9-1.4)$ & 0.157 & & \\
\hline \multicolumn{7}{|l|}{ Portal vein thrombosis } \\
\hline No & 1176 & 678 & 1 & & 1 & \\
\hline Yes & 309 & 190 & $1.2(1.0-1.4)$ & 0.048 & $1.1(0.7-1.6)$ & 0.084 \\
\hline \multicolumn{7}{|l|}{ BCLC stages } \\
\hline $0-\mathrm{A}$ & 585 & 305 & 1 & & 1 & \\
\hline B & 542 & 330 & $1.4(1.2-1.6)$ & $<0.001$ & $2.6(1.6-4.3)$ & $<0.001$ \\
\hline C & 318 & 203 & $1.5(1.3-1.8)$ & $<0.001$ & $2.8(1.6-4.9)$ & $<0.001$ \\
\hline $\mathrm{D}$ & 40 & 30 & $2.5(1.7-3.6)$ & $<0.001$ & $3.1(1.9-5.0)$ & $<0.001$ \\
\hline \multicolumn{7}{|l|}{ Primary treatments } \\
\hline Supportive treatments & 126 & 107 & 1 & & 1 & \\
\hline Locoregional therapies & 702 & 413 & $0.2(0.1-0.2)$ & $<0.001$ & $0.2(0.1-0.2)$ & $<0.001$ \\
\hline Surgical resection & 623 & 333 & $0.1(0.1-0.2)$ & $<0.001$ & $0.1(0.1-0.2)$ & $<0.001$ \\
\hline Liver transplant & 34 & 15 & $0.1(0.1-0.2)$ & $<0.001$ & $0.1(0.1-0.2)$ & $<0.001$ \\
\hline
\end{tabular}

Events, patient death during follow-up; HR, hazard ratio; CI, confidence interval; BCLC, Barcelona Liver Cancer; CNY, Chinese Yuan (1 CNY $\approx 0.146$ USD)

Household income was closely relevant to, but not determined by education level. Similar to some previous studies on other tumor types [6, 16, 20], patients with low income had more advanced HCC stages, less aggressive treatments received, higher 30-day mortality and poorer long-term survival than those with high income. This association was also manifested in surgical resected HCC patients. Lower household income, but not education level, was identified as independent risk factor of the survival of HCC patients. Patients with low income may be exposed to unhealthy lifestyle or environmental factors, be less intensively screened for HCC, less adherent to any treatments, which lead to more aggressive disease and poorer outcome [6, 16, 20,21].

Although closely correlated to each other, education and income are separate constructs and have different impacts on diagnosis, treatment and prognosis of HCC. While both education and income may be associated with economic resources, education can also reflect noneconomic social characteristics that influence health such as health-related knowledge, acceptance of invasive treatments, and influence one's lifestyle [21, 22]. Income can reflect "ability to pay" in cancer screening, diagnosis, treatment and post-treatment checkup [23]. Therefore, more effort should be placed on the lower educated patients, as they could have more risk of late diagnosis, less treatment, higher mortality, as presented in our study. Moreover, efforts from the whole society should be made continuously to support the patients in poverty in cancer screening, diagnosis, and treatments.

Residence of the patients was closely associated with education and income. People with higher education and income are more likely to live in large 
cities, while those with lower education and income are more likely to live in rural places. This is called "Urban-Rural Gap" which has been noticed for several decades by the whole society and government [24]. Interestingly, we found no significant difference of long-term outcome between the patients living in urban and in rural places as whole or after surgical resection. These findings might imply certain socioeconomic changes in the country that the urban-rural gap is narrowing, although the imbalance of education, health and living resources is still huge [25]. To reduce the long-standing gap and insuring the rural population against health and economic risk, the Chinese government launched the New Rural Cooperative Medical System in 2003, which covers $95.3 \%$ of the rural population of China by 2011 [26, 27].

There are several limitations of the present study. First, this is a retrospective study conducted in one single center. All the data were collected retrospectively, thus weakened by certain inherent biases. Second, education level was documented only for the patients at admission. However, in China, concealment of diagnosis and prognosis from cancer patients is still common and not all the cancer patients would be fully informed of their diagnosis, treatment and expected prognosis [28]. Diagnosis and treatments are usually discussed by family members of the patients and physicians. Therefore, the impact of education level of patients on cancer prognosis would be substantially weakened. However, education level of their families is hard to collect and determine. Third, income is rather complex to measure. Patients and their family members tended to underreport the household income, since some income as bonus might not be reported. Last, the present study has been conducted based on hospitalized patients who were eager to be treated. As we believe, there were still many HCC patients, especially those with low education level and household income, and living in rural places, refusing any invasive treatments in hospital but relying on some folk remedies. Therefore, impacts of socioeconomic status on cancer patient survival should be more significant if taking all the inpatients and outpatients into account.

\section{Conclusion}

The present study has shown that HCC patients with less education and lower household income presented with more advanced disease progression at diagnosis, received less effective treatments, and had higher mortality and poorer long-term survival. Intervention strategies targeting patients with less education and lower income should be evaluated to improve the outcomes of HCC by routine screening, early diagnosis and effective treatments. Further studies based on national health database with enrollment of both inpatients and outpatients should be performed, especially in China with great changes in society, law and economics in recent 40 years.

\section{Acknowledgement}

This study was supported in part by National Natural Science Foundation (NO. 81372582), "New-Star" Young Scientists in Shaanxi Province Programme (2014kjxx-30), and the Fundamental Research Funds for the Central Universities.

\section{Competing Interests}

The authors have declared that no competing interest exists.

\section{References}

1. Torre LA, Bray F, Siegel RL, et al. Global cancer statistics, 2012. CA Cancer J Clin. 2015;65:87-108.

2. Torre LA, Siegel RL, Ward EM, et al. Global Cancer Incidence and Mortality Rates and Trends--An Update. Cancer Epidemiol Biomarkers Prev. 2016;25:16-27.

3. Chen JG, Zhang SW. Liver cancer epidemic in China: past, present and future. Semin Cancer Biol. 2011;21:59-69.

4. Llovet JM, Burroughs A, Bruix J. Hepatocellular carcinoma. Lancet. 2003;362:1907-17.

5. Shaw JJ, Shah SA. Rising incidence and demographics of hepatocellular carcinoma in the USA: what does it mean? Expert Rev Gastroenterol Hepatol. 2011;5:365-70.

6. Clegg LX, Reichman ME, Miller BA, et al. Impact of socioeconomic status on cancer incidence and stage at diagnosis: selected findings from the surveillance, epidemiology, and end results: National Longitudinal Mortality Study. Cancer Causes Control. 2009;20:417-35.

7. Jemal A, Clegg LX, Ward E, et al. Annual report to the nation on the status of cancer, 1975-2001, with a special feature regarding survival. Cancer. 2004;101:3-27.

8. Ward E, Jemal A, Cokkinides V, et al. Cancer disparities by race/ethnicity and socioeconomic status. CA Cancer J Clin. 2004;54:78-93.

9. Cavalli-Bjorkman N, Lambe M, Eaker S, et al. Differences according to educational level in the management and survival of colorectal cancer in Sweden. Eur J Cancer. 2011;47:1398-406.

10. Eloranta S, Lambert PC, Cavalli-Bjorkman N, et al. Does socioeconomic status influence the prospect of cure from colon cancer--a population-based study in Sweden 1965-2000. Eur J Cancer. 2010;46:2965-72.

11. Brusselaers N, Ljung R, Mattsson F, et al. Education level and survival after oesophageal cancer surgery: a prospective population-based cohort study. BMJ Open. 2013;3:e003754.

12. Byers TE, Wolf HJ, Bauer KR, et al. The impact of socioeconomic status on survival after cancer in the United States : findings from the National Program of Cancer Registries Patterns of Care Study. Cancer. 2008;113:582-91.

13. Coleman MP, Rachet B, Woods LM, et al. Trends and socioeconomic inequalities in cancer survival in England and Wales up to 2001. Br J Cancer. 2004;90:1367-73.

14. Kokabi N, Xing M, Duszak R, Jr., et al. Sociodemographic impact on survival in unresectable hepatocellular carcinoma: a survival epidemiology and end results study. Future Oncol. 2016;12:183-98.

15. El-Serag HB, Davila JA, Petersen NJ, et al. The continuing increase in the incidence of hepatocellular carcinoma in the United States: an update. Ann Intern Med. 2003;139:817-23.

16. Hoehn RS, Hanseman DJ, Jernigan PL, et al. Disparities in care for patients with curable hepatocellular carcinoma. HPB (Oxford). 2015;17:747-52.

17. Shaya FT, Breunig IM, Seal B, et al. Comparative and cost effectiveness of treatment modalities for hepatocellular carcinoma in SEER-Medicare. Pharmacoeconomics. 2014;32:63-74.

18. Tan D, Yopp A, Beg MS, et al. Meta-analysis: underutilisation and disparities of treatment among patients with hepatocellular carcinoma in the United States. Aliment Pharmacol Ther. 2013;38:703-12.

19. Zhang Y. History and Future of the National College Entrance Exam (NCEE) in China. National College Entrance Exam in China: Springer Singapore; 2016:1-15.

20. Chen MF, Yang $\mathrm{YH}$, Lai $\mathrm{CH}$, et al. Outcome of patients with esophageal cancer: a nationwide analysis. Ann Surg Oncol. 2013;20:3023-30. 
21. Sprague BL, Trentham-Dietz A, Gangnon RE, et al. Socioeconomic status and survival after an invasive breast cancer diagnosis. Cancer. 2011;117:1542-51.

22. Braveman PA, Cubbin C, Egerter S, et al. Socioeconomic status in health research: one size does not fit all. JAMA. 2005;294:2879-88.

23. Franzini L, Williams AF, Franklin J, et al. Effects of race and socioeconomic status on survival of 1,332 black, Hispanic, and white women with breast cancer. Ann Surg Oncol. 1997;4:111-8.

24. Liu GG, Dow WH, Fu AZ, et al. Income productivity in China: on the role of health. J Health Econ. 2008;27:27-44.

25. Peng $X$, Song $S$, Sullivan $S$, et al. Ageing, the urban-rural gap and disability trends: 19 years of experience in China - 1987 to 2006. PLoS One. 2010;5:e12129.

26. Zhang $Y$, Chen $Y$, Zhang $X$, et al. Current level and determinants of inappropriate admissions to township hospitals under the new rural cooperative medical system in China: a cross-sectional study. BMC Health Serv Res. 2014;14:649.

27. NHFPC, NHaFPCoC. 2013 China Statistics Yearbook of Health and Family Planning. Beijing: Peking Union Medical College Press; 2013.

28. Tieying $Z$, Haishan $H$, Meizhen $Z$, et al. Health professionals' attitude towards information disclosure to cancer patients in China. Nurs Ethics. 2011:18:356-63. 